\title{
Direct and In-Direct Strength Evaluation of Refractory Structural Elements Subjected to Temperature Cycles
}

\author{
Ganesh D. Awchat ${ }^{1 *}$ \\ 1 Department of Civil Engineering, Shri Guru Gobind Singhji Institute of Engineering \& Technology, Nanded \\ 431606, Maharashtra, India \\ *E-mail: gdawchat@gmail.com
}

\begin{abstract}
Refractory structural elements used in the lining work of refractory are exposed to a more complex stress-strain behavior due to the temperature variation cycle. To investigate the performance of refractory structural elements, an attempt was made in this research to cast Aluminium Oxide, i.e., $80 \% \mathrm{Al}_{2} \mathrm{O}_{3}$ castable in the form of cubes of $150 \times 150 \times 150 \mathrm{~mm}$ size and heated to different temperatures of $100^{\circ} \mathrm{C}$ to $800^{\circ} \mathrm{C}$. Rebound Hammer Test, Ultrasonic Pulse Velocity (UPV) test performed to evaluate compressive strength of refractory structural elements qualitatively and quantitatively. Direct compressive strength of identical heated cube specimens investigated using a compression testing machine. The relationship between direct and indirect test results of compressive strength was established and compared. Four different grade bricks B-1, B-2, B-3, and B-4 heated to $800{ }^{\circ} \mathrm{C}$ to study the formation of microcracks at high temperatures. The bricks were fired for $0,2,4,6,8$, and 10 cycles up to $800{ }^{\circ} \mathrm{C}$ and same used for UPV testing, Modulus of Rupture (MoR) tests. The study aimed to correlate direct and indirect strength results helpful in selecting suitable refractory materials in practice. UPV test values plotted with cube specimen heated at $100{ }^{\circ} \mathrm{C}$ to $800^{\circ} \mathrm{C}$ revealed that UPV values decrease as temperature increases. The compressive strength of cubes increased with temperature due to the evaporation of water vapor in the matrix and the ceramic bonding effect, which increased cube compressive strength after heating. The graph of the relationship between MoR and UPV for all grade bricks at five heating cycles up to $800{ }^{\circ} \mathrm{C}$ revealed thermal cracks observed in all B-2 bricks only after third loading cycles. For other specimens, the proportionality relationship between them is linear. The experimental outcome of research provides technical support for the selection of structural elements material in refractory.
\end{abstract}

Keywords: refractory structural elements, non destructive testing, aluminium oxide rebound hammer test, ultrasonic pulse velocity test, compressive strength, flexural strength.

\section{INTRODUCTION}

Furnaces are built and operated to withstand extreme temperature, mechanical, and chemical environments. To protect the structure from the harsh operating area in furnaces lined with refractory castables as bricks. Refractory linings in furnaces deteriorate and wear over time. Thermal stresses and chemical attacks are the primary causes of deterioration, resulting in heat transfer and load-bearing capabilities. Failure of the lining is dangerous and can affect the structural integrity of the furnace. The degree and mechanism of deterioration depend on different factors.
Non-destructive methods were observed effectively in structural strength assessment by examining and monitoring the extent of the damage [1]. The accuracy of these indirect NDT methods relies essentially on the quality and homogeneity of the refractory materials in the refractory lining [2]. Regular NDT evaluation, combined with the control system data, helps to extend refractory's campaign life and the lifespan of its structural components [3]. Rebound Hammer is unable to provide a reliable estimate of concrete strength. It is most likely due to the test's minimal area, allowing small local inhomogeneities to impact the test. As a result, the rebound hammer appears 
ineffective in estimating concrete compressive strength, serving only as a rough tool for assessing material homogeneity within a specific concrete type [4]. Refractory structures exposed to a more complicated load environment, thermal expansion loading. The refractory lining is exposed to high temperatures resulting complex stress/ strain environment within the lining structure. The refractory material properties tend to vary as a linear function of temperature. High temperature has a profound influence on the refractory material properties. At high temperatures, refractory materials have no longer remain elastic [5]. For more than three decades, NDT methods were used to monitor concrete structures; now, it is recognized that NDT plays a vital role in monitoring existing RC structures. NDT methods are more practical for assessing and evaluating the condition of RC structures [6]. Almir and Protasio used NDT methods to determine the compressive strength of concrete and presented the validity of pull off, pin penetration, and UPV for determining concrete strength [7]. Bhadauria and Gupta presented a case study of deteriorating water tanks in India's semitropical region. Concrete cover, carbonation depth, chloride concentration, compressive strength, and other parameters are all measured. Cover meter, Phenolphthalein indicator test, Quantab test, Potentiometric Titration, Schist's hammer test, and UPV test used as NDT methods for selection of refractory materials[8]. Maierhofer et al. reviewed several methods and discussed the planning and implementation of NDT methods for structural health monitoring [9]. Non-Destructive Techniques (NDT) to assess concrete defects and quality have gotten extraordinary significance in the ongoing past. These procedures have their advantages and limitations compared to regular strength assessment and damage detection tests $[10,11]$. Schacht carried out a thorough literature search and experimental work to identify refractory deterioration under different thermal loadings and material [12]. Essen studied structures subjected to extreme thermal loading, observed refractory elements behavior as more complex [13]. Walker introduced the NDT method to monitor refractory structural elements at a site without damaging the existing structure to address that complexity. Non-destructive testing in the refractory field for identifying crushing strength, cracks, crack depth, etc. NDT can be used to monitor refractory in all industries which use refractory material [14]. Weidner et al. studied equipment like reheating furnaces, boiler, heater, reactor, cement plants, fertilizers lined with a heat resistant material called "Refractory" material. They observed that refractories are heat-safe materials that comprise the linings for high-temperature furnaces and reactors, and other preparing units. Notwithstanding being impervious to thermal stress and other physical phenomena instigated by heat, refractories should likewise withstand physical wear and erosion by chemical agents [15]. Sadik et al. studied that refractories are more warmth safe than metals and are needed for heating applications above $1000^{\circ} \mathrm{F}$ (i.e., $538^{\circ} \mathrm{C}$ ) [16]. Frulli et al. studied the properties and application of Andalusite-based raw materials for refractory castable. They found that Andalusite has intrinsic properties, once sintered (mullite precursor, composite microstructure, and thermal shock resistance) that yields castable and brick that exhibit very high thermo-mechanical stability [17]. Bolborea et al. developed a new methodology to predict the concrete compressive strength through ultrasonic testing. They found that a high accuracy rate makes the ultrasonic testing method suitable for further investigations to establish a reliable NDT methodology that could substitute the very invasive and less convenient destructive method [18].

No scientific methodology is available for assessing compressive strength, MoR based on NDT results of the refractory unit. Research work carried out in two parts to establish a relationship between direct and NDT results. In the first part, non-destructive testing of Aluminium Oxide, i.e., $80 \% \mathrm{Al}_{2} \mathrm{O}_{3}$ castable as cubes using Rebound Hammer test and UPV test carried out \& compressive strength obtained from destructive method compared and discussed. In the second part, four different grade bricks were heated to $0,2,4,6,8$ and 10 cycles up to $800{ }^{\circ} \mathrm{C}$ and tested indirectly using UPV and directly by MoR. The relationship between laboratory testing results and NDT results established for cubes and bricks for quick judgment values based on different strengths using NDT and destructive tests.

\section{OBJECTIVES OF RESEARCH}

The present work establishes a relationship between direct and indirect results for accepting refractory structural material for cast in situ construction of furnaces. Following are the problem discussed in the current study: 
- To apply non-destructive techniques, i.e., rebound hammer and UPV test that can effectively assess strength qualitatively and quantitatively and to compare results with destructive compressive strength.

- To cast different grade bricks and heated for 0 , 2, 4, 6, 8 and 10 cycles from $100^{\circ} \mathrm{C}$ to $800^{\circ} \mathrm{C}$ for studying the formation of microcracks at different temperatures.

- To validate the strength and limitations of applicable destructive and NDT techniques from the perspective of accuracy, precision, ease of use.

- To provide technical literature for the selection of structural elements material in refractory.

\section{METHODOLOGY}

Aluminum Oxide cubes made up of $80 \%$ $\mathrm{Al}_{2} \mathrm{O}_{3}$ cast to assess rebound index ( $\mathrm{R}$ ) and UPV and details about dimensions and heating temperature of cubes specimens presented in Table 1. Fresh $80 \% \mathrm{Al}_{2} \mathrm{O}_{3}$ concrete test cubes prepration presented in Figure 1.

\section{Rebound hammer test}

The following are specifications of original Schmidt digital rebound hammer (Type N) Swiss - made. a) Impact energy : 2.207 N. m

b) Display: Analog and back lit digital (100x100 px)

c) Power requirement:AAA battery

d) Charger connection: Micro-USB

e) Productdimensions:274.3x83.8x61 mm $(\mathrm{W} \times \mathrm{DxH})$

The following methodology is proposed for testing cube samples using the rebound hammer test.

- For testing, a smooth, clean, and dry surface are to be selected. If a loosely adhering scale is present, this should rub with a grinding wheel or stone. Rough surfaces resulting from insufficient compaction, grout loss do not give reliable results and should be avoided.

- The point of impact should be at least $20 \mathrm{~mm}$ away from any edge or shape discontinuity.

- For taking a measurement, the rebound hammer is kept at right angles to the surface of the concrete member. The test can thus be conducted horizontally on vertical surfaces or vertically upwards or downwards on horizontal surfaces. If the situation demands, the rebound hammer can also be held at intermediate angles, but in each case, the rebound number will be different for the same concrete.

Rebound hammer test locations was marked for each cube specimen presented in Figure 2 and Figure 3 illustrated graphical testing procedure for application of rebound hammer on test samples.

Table 1. Details of cube specimens

\begin{tabular}{|c|c|c|c|}
\hline Cube ID & Size $(\mathrm{mm} \times \mathrm{mm} \times \mathrm{mm})$ & Specimen & Heating temp. (“' C”) \\
\hline C-0 & $150 \times 150 \times 150$ & 3 Nos. & 100 \\
\hline C-1 & $150 \times 150 \times 150$ & 3 Nos. & 200 \\
\hline C-2 & $150 \times 150 \times 150$ & 3 Nos. & 300 \\
\hline C-3 & $150 \times 150 \times 150$ & 3 Nos. & 400 \\
\hline C-4 & $150 \times 150 \times 150$ & 3 Nos. & 500 \\
\hline C-5 & $150 \times 150 \times 150$ & 3 Nos. & 600 \\
\hline C-6 & $150 \times 150 \times 150$ & 3 Nos. & 700 \\
\hline C-7 & $150 \times 150 \times 150$ & 3 Nos. & 800 \\
\hline
\end{tabular}
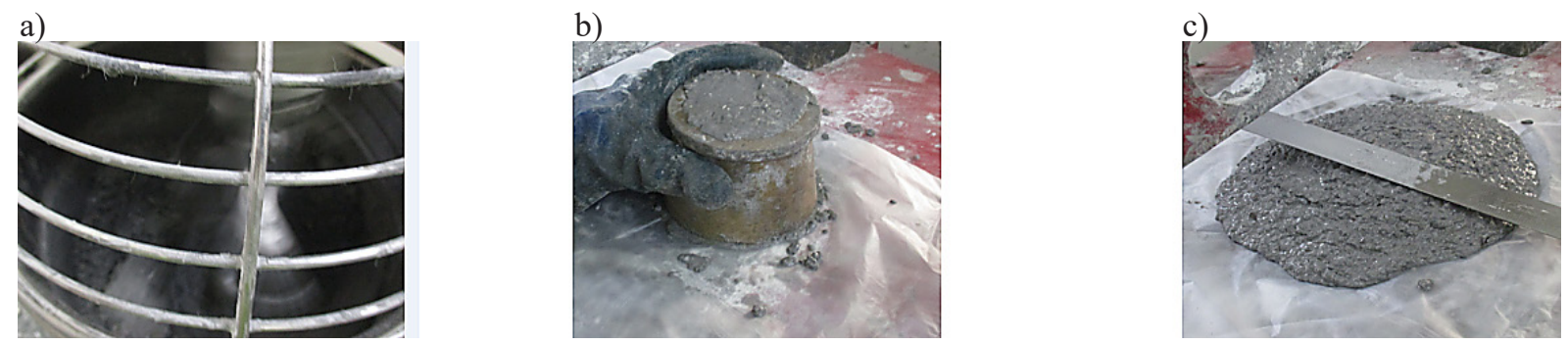

Fig. 1. Fresh $80 \% \mathrm{Al}_{2} \mathrm{O}_{3}$ concrete test cubes prepration; a)Hobart Mixer, b) Slump cone test, c) Consistency test 


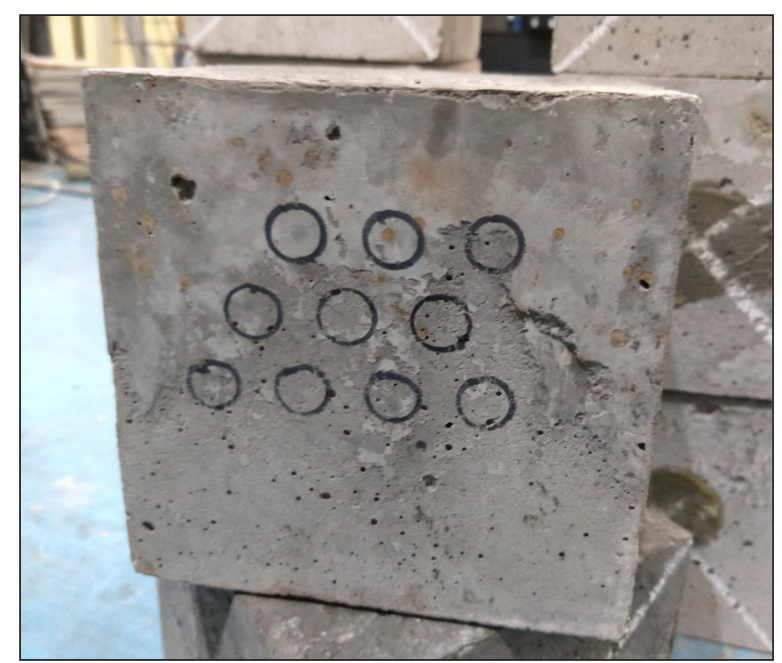

Fig. 2. Rebound Hammer test locations

The Rebound Hammer Method based on a rebound of an elastic mass depends on the hardness of the concrete surface against which the mass strikes. When the plunger of the rebound hammer is pressed against the concrete surface and the spring-controlled mass in the hammer rebounds. The amount of rebound of the mass depends on the hardness of the concrete surface. The standards on which it works depend on the bounceback effect of a hammer as a piston that rests against the concrete's surface under test; the more prominent opponents of the concrete, the more noteworthy the rebound index. By perusing such bounce rebound index as an effect on a scale and relating it to curves provided with the instrument, the resistance from compression strength (Fck) in $\mathrm{MPa}$ was found out [10].

\section{Ultrasonic pulse velocity}

The ultrasonic pulse velocity method measures the time of travel of an ultrasonic pulse, passing through the concrete specimen to be tested. The pulse generator circuit consists of an electronic circuit for generating pulses and a transducer for transforming these electronic pulses into mechanical energy having vibration frequencies in the range of 20 to $500 \mathrm{kHz}$. The time of travel between initial onset and the reception of the pulse is measured electronically. The path length between transducers divided by travel time in microseconds gives the average wave propagation velocity. Ultrasonic pulse velocity test conducted following IS:13311(Part 1) -1992 [10]. The direct transmission method is used to find out UPV presented in Figure 4. The graphical illustration of UPV test indicated in Figure 5.

The following are specifications of device used for the measurement of UPV values presented as follows:bandwidth: 20 to $500 \mathrm{KHz}$, pulse voltage: 125 to $500 \mathrm{~V}$ (UPV), measuring resolution: $0.1 \mu \mathrm{s}$, Receiver gain: $1 \mathrm{x}, 10 \mathrm{x}, 100 \mathrm{x}$ and AUTO.
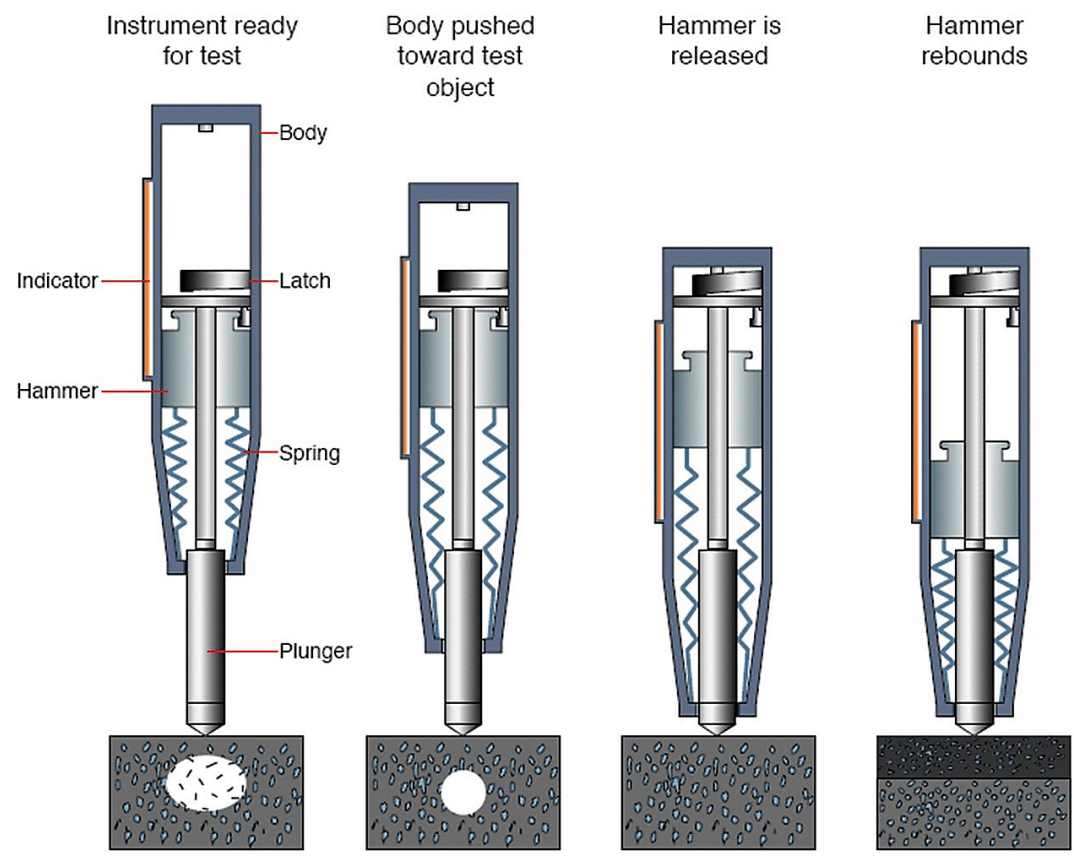

Fig. 3. Graphical illustration of Rebound Hammer Test 

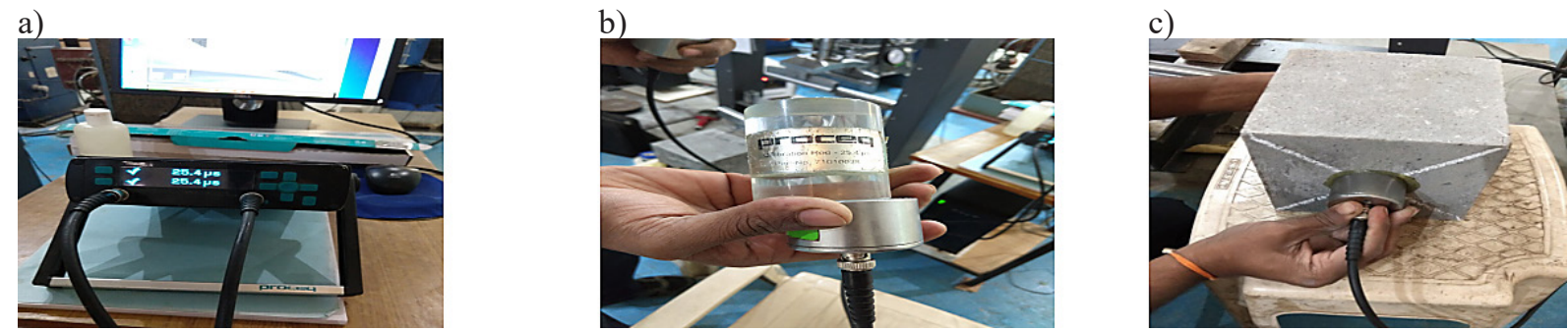

Fig. 4. Ultrasonic Pulse Velocity Test procedure; a) UPV machine, b) Calibration sample, c) UPV measurement

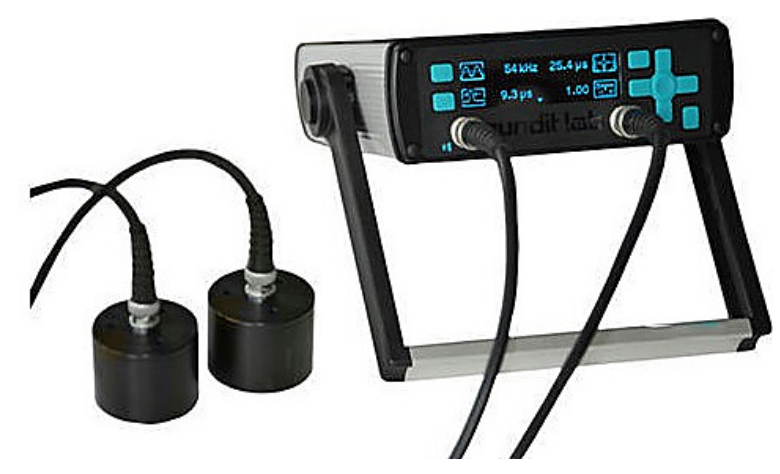

Fig. 5. Graphical illustration of UPV Test

\section{Cube compressive strength test}

A compressive strength test was carried on a sample of cube specimens of size $(150 \mathrm{~mm} x$ $150 \mathrm{~mm} \times 150 \mathrm{~mm}$ ) made up of $80 \% \mathrm{Al}_{2} \mathrm{O}_{3}$ \& presented in Figure 6.

\section{Study of Micro crack formation}

Based on destructive and non-destructive laboratory results, it was observed that due to micro-cracks formation inside the cube, the time travel increases, and UPV gets reduced at $800{ }^{\circ} \mathrm{C}$ temperature. Micro crack propagation at $0,2,4$, 6,8 and 10 cycles of heating under a maintained temperature of $800{ }^{\circ} \mathrm{C}$ for each process considered to obtain MoR. Details of brick specimens are presented in Table 2 and Figure 7, and UPV testing illustrated in Figure 8.

MoR and UPV tests were carried out to understand the development of micro-cracks inside the refractory materials. Microcracks were developed in the bricks by thermal shock to the refractory material in $0,2,4,6,8$ and 10 cycles.

\section{RESULTS AND DISCUSSIONS}

A rebound hammer test is conducted around all the observation points on all accessible faces of the castable cubes. Concrete surfaces are thoroughly cleaned before taking any measurement. Ten readings of rebound indices are taken, and an average of these readings after deleting outliers as per

Table 2. Details of brick specimens

\begin{tabular}{|c|c|c|c|c|}
\hline $\begin{array}{c}\text { Sample } \\
\text { ID }\end{array}$ & Composition & $\begin{array}{c}\text { Size } \\
(\mathrm{mm} \times \mathrm{mm} \times \mathrm{mm})\end{array}$ & Specimen & $\begin{array}{c}\text { Heating Temp. } \\
(\text { "0 C") }\end{array}$ \\
\hline B-1 & Clay based bricks & $230 \times 115 \times 75$ & 3 Nos. & 800 \\
\hline B-2 & Clay and low-grade alumina based bricks & $230 \times 115 \times 75$ & 3 Nos. & 800 \\
\hline B-3 & Bauxite based bricks & $230 \times 115 \times 75$ & 3 Nos. & 800 \\
\hline B-4 & Phosphate bonded high alumina bricks & $230 \times 115 \times 75$ & 3 Nos. & 800 \\
\hline
\end{tabular}

a)

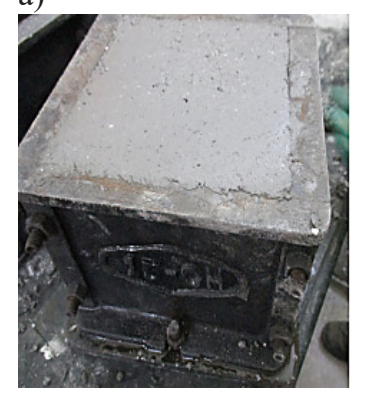

b)

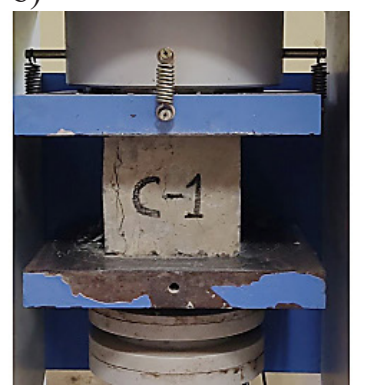

c)

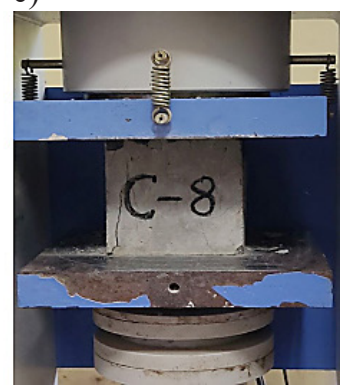

Fig. 6. Compressive strength set up; a) Casting of cube specimen, b) Tested C-1 specimen, c) Tested C-8 specimen 


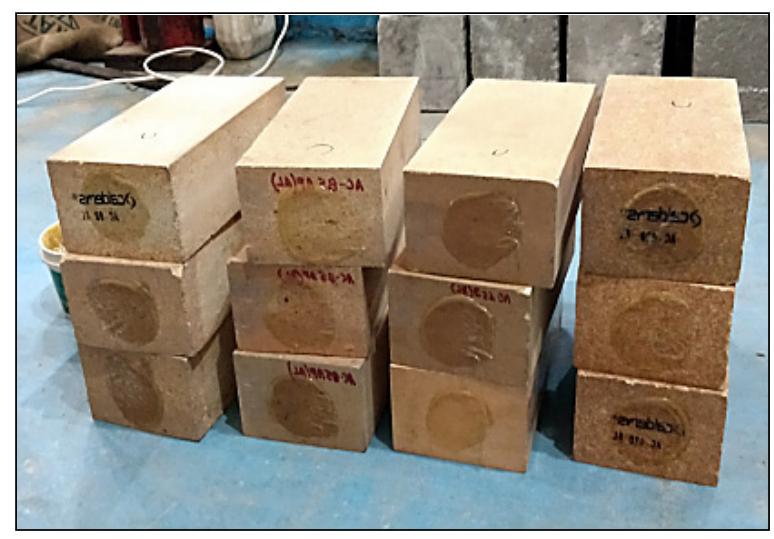

Fig. 7. Brick samples of four grades

IS:8900-1978 [19] becomes the rebound index for the point of observation. Average rebound indices for each cube specimen were recorded using a rebound hammer, as shown in Table 3.

Table 3 showed the increasing trend of average rebound number value for C-1, C-2, C-3,

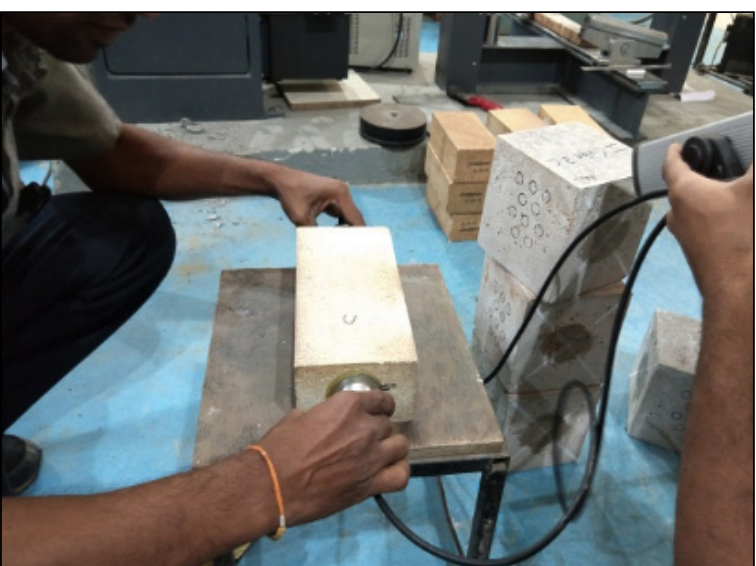

Fig. 8. Ultrasonic pulse velocity test

$\mathrm{C}-4, \mathrm{C}-5, \mathrm{C}-6, \mathrm{C}-7$, and $\mathrm{C}-8$ subjected to $100^{\circ} \mathrm{C}$, $200{ }^{\circ} \mathrm{C}, 300{ }^{\circ} \mathrm{C}, 400{ }^{\circ} \mathrm{C}, 500{ }^{\circ} \mathrm{C}, 600{ }^{\circ} \mathrm{C}, 700{ }^{\circ} \mathrm{C}$, and $800^{\circ} \mathrm{C}$ temperature respectively. It observed that Fck of C-1, C-2, C-3, C-4, C-5, C-6, C-7, and $\mathrm{C}-8$ is $14.19 \%, 17.12 \%, 18.56 \%, 20.90 \%$,

Table 3. Rebound Index (R) and Fck results for castable cubes

\begin{tabular}{|c|c|c|c|c|c|c|c|c|c|c|c|c|c|c|}
\hline \multirow{2}{*}{$\begin{array}{c}\text { Cube } \\
\text { ID }\end{array}$} & \multirow{2}{*}{ ID } & \multicolumn{10}{|c|}{ Rebound Number (R) } & \multirow{2}{*}{ MeanR } & \multirow{2}{*}{$\begin{array}{c}R \\
\text { Avg. }\end{array}$} & \multirow{2}{*}{$\begin{array}{c}F_{c k} \\
(\mathrm{MPa})\end{array}$} \\
\hline & & 1 & 2 & 3 & 4 & 5 & 6 & 7 & 8 & 9 & 10 & & & \\
\hline \multirow{3}{*}{$\mathrm{C}-0$} & I & 32.9 & 35 & 37.1 & 34.5 & 35 & 36.7 & 34.2 & 33.8 & 37 & 37.5 & 35.4 & \multirow{3}{*}{35} & \multirow{3}{*}{34.7} \\
\hline & II & 32.4 & 36.4 & 33.2 & 33.6 & 36.3 & 34.4 & 34.3 & 36.5 & 35 & 37.5 & 35.0 & & \\
\hline & III & 31.9 & 34.5 & 36.1 & 33.8 & 34 & 35.7 & 33.2 & 32.8 & 36 & 37.1 & 34.5 & & \\
\hline \multirow{3}{*}{ C-1 } & I & 34.5 & 39.5 & 43.5 & 38.5 & 42.5 & 36.5 & 36.5 & 46 & 42 & 43.5 & 40.3 & \multirow{3}{*}{40.1} & \multirow{3}{*}{40} \\
\hline & II & 38 & 40 & 39.5 & 41.5 & 39 & 41 & 40 & 40 & 39.5 & 42 & 40.1 & & \\
\hline & III & 33.5 & 41.5 & 38 & 37.5 & 39.5 & 41 & 42.5 & 42 & 40 & 44 & 40.0 & & \\
\hline \multirow{3}{*}{$\mathrm{C}-2$} & I & 38.5 & 40.5 & 42 & 41.5 & 42.5 & 42 & 40 & 39.5 & 43 & 43.5 & 41.3 & \multirow{3}{*}{41.3} & \multirow{3}{*}{41.2} \\
\hline & II & 38.5 & 40 & 44 & 39 & 39 & 40 & 38.5 & 42 & 43.5 & 44 & 40.9 & & \\
\hline & III & 39.5 & 41 & 40 & 41.5 & 43 & 41.5 & 43.5 & 39.5 & 43.5 & 44 & 41.7 & & \\
\hline \multirow{3}{*}{ C-3 } & I & 39 & 43 & 41.5 & 42.5 & 42 & 40 & 41 & 40 & 43 & 43.5 & 41.6 & \multirow{3}{*}{42} & \multirow{3}{*}{41.8} \\
\hline & II & 38 & 43 & 40.5 & 40 & 42 & 45 & 43.5 & 44.5 & 42.5 & 46.5 & 42.6 & & \\
\hline & III & 36 & 41 & 42 & 42 & 43 & 43 & 40 & 42 & 45 & 46 & 42.0 & & \\
\hline \multirow{3}{*}{ C-4 } & I & 42.5 & 44 & 44.5 & 47 & 46.5 & 48 & 47.5 & 42.5 & 43.5 & 48.5 & 45.5 & \multirow{3}{*}{43} & \multirow{3}{*}{42.8} \\
\hline & II & 32.5 & 43 & 38.5 & 41 & 38 & 39 & 42 & 39 & 35.5 & 46 & 39.5 & & \\
\hline & III & 37.5 & 42 & 45 & 49 & 43 & 49 & 44 & 42.5 & 39.5 & 50.5 & 44.2 & & \\
\hline \multirow{3}{*}{ C-5 } & I & 42 & 44 & 45 & 46 & 46.5 & 46 & 46 & 43.5 & 43.5 & 47 & 45 & \multirow{3}{*}{44.4} & \multirow{3}{*}{44.3} \\
\hline & II & 40 & 40.5 & 42.5 & 41.5 & 40 & 42 & 44 & 40 & 43.5 & 44 & 41.8 & & \\
\hline & III & 39 & 45 & 50 & 49 & 48 & 49 & 44 & 45 & 45 & 50 & 46.4 & & \\
\hline \multirow{3}{*}{ C-6 } & I & 37.5 & 42 & 45 & 47 & 43 & 47 & 44 & 42.5 & 40 & 48.5 & 43.7 & \multirow{3}{*}{45.9} & \multirow{3}{*}{45.7} \\
\hline & II & 40 & 48 & 45 & 51 & 50 & 49 & 46 & 50 & 45 & 52 & 47.6 & & \\
\hline & III & 39 & 48 & 49 & 50 & 44 & 45 & 45 & 49 & 45 & 50 & 46.4 & & \\
\hline & I & 42.5 & 48 & 47 & 46 & 44.5 & 43.5 & 44 & 47.5 & 43 & 48.5 & 45.5 & & \\
\hline C-7 & II & 45 & 49 & 49 & 50.5 & 50.5 & 49 & 48 & 50 & 47 & 52.5 & 49.1 & 47 & 46.8 \\
\hline & III & 39 & 48 & 49 & 50 & 49 & 46 & 45 & 45 & 43 & 50 & 46.4 & & \\
\hline & 1 & 40 & 50.5 & 48.5 & 50 & 51 & 43.5 & 50 & 42 & 52 & 52.5 & 48 & & \\
\hline C-8 & II & 45 & 48 & 45.5 & 47.5 & 46.5 & 48 & 47.5 & 45.5 & 47 & 50.5 & 47.1 & 48.5 & 48.2 \\
\hline & III & 43 & 50 & 47 & 49 & 54.5 & 49 & 55 & 51 & 48.5 & 57 & 50.4 & & \\
\hline
\end{tabular}


$24.30 \%, 27.36 \%, 29.69 \%$ and $32.56 \%$ higher than $\mathrm{C}-0$ respectively due to strong covalent ceramic bonding effect, which increases the compressive strength resistance to Schmidt rebound hammer. The Rebound Index (R) of 10 samples of cube C-0 obtained as $32.9,35,37.1$, $34.5,35,36.7,34.2,33.8,37$, and 37.5. The doubtful observation for uncertainty analysis is the lowest and highest value, $\mathrm{x}_{1}=32.9$ and $\mathrm{x}_{10}$ $=37.5$, respectively. The mean $\overline{\mathrm{X}}$ and standard deviation (S) for the 10 results are $\mathrm{n}=10$,

$$
\begin{gathered}
\bar{X}=\frac{x_{1}+x_{2}+x_{3} \ldots x_{n}}{n}=\frac{\sum_{i=1}^{n} x_{i}}{n}=35.4, \\
S=\sqrt{\frac{\sum_{i=1}^{n}\left(x_{i}-\bar{X}\right)^{2}}{n-1}}=1.5962 .
\end{gathered}
$$$$
\text { Then, } \mathrm{T}_{1}=\frac{35.4-32.9}{1.5962}=1.5662
$$

$$
\text { and, } \mathrm{T}_{10}=\frac{37.5-35.4}{1.5962}=1.3156 .
$$

Since the calculated value (1.5662) of and (1.3156) of is less than the tabulated value of (2.176) and (2.410) in Table 1 for the size of the reading 10,1 percent and 5 percent level of significance [19], the lowest and highest value in the readings may be treated as inlier and accepted. A similar method was adopted for uncertainty analysis of Rebound Index (R) results of $80 \% \mathrm{Al}_{2} \mathrm{O}_{3}$ castable cubes and presented in Table 4.

UPV test results of C-0 i.e. $\mathrm{x}_{1}=4966 \mathrm{~m} /$ sec, $x_{2}=5168 \mathrm{~m} / \mathrm{sec}$ and $\mathrm{x}_{\mathrm{n}}=5216 \mathrm{~m} / \mathrm{sec}$ arranged in the ascending order of magnitude. The smallest value $r_{10}=\frac{x_{2}-x_{1}}{x_{n}-x_{1}}$ and Largest value $r_{10}=\frac{x_{n}-x_{n-1}}{x_{n}-x_{1}}$ calculated . The ratio of smallest and largest value does not exceed the corre-

\begin{tabular}{|c|c|c|c|c|c|c|c|}
\hline \multirow{2}{*}{$\begin{array}{l}\text { Cube } \\
\text { ID }\end{array}$} & \multirow{2}{*}{ ID } & \multirow{2}{*}{$\begin{array}{c}\text { Mean } \\
\bar{X}\end{array}$} & \multirow{2}{*}{$S$} & \multirow{2}{*}{$\mathrm{T}_{1}$} & \multirow{2}{*}{$\mathrm{T}_{10}$} & \multicolumn{2}{|c|}{ Significance level } \\
\hline & & & & & & $5 \%$ & $1 \%$ \\
\hline \multirow{3}{*}{$\mathrm{C}-0$} & 1 & 35.4 & 1.5962 & 1.5662 & 1.3156 & 2.176 & 2.410 \\
\hline & II & 35.0 & 1.6653 & 1.5612 & 1.5012 & 2.176 & 2.410 \\
\hline & III & 34.5 & 1.6697 & 1.5571 & 1.5571 & 2.176 & 2.410 \\
\hline \multirow{3}{*}{ C-1 } & 1 & 40.3 & 3.7580 & 1.5434 & 0.8515 & 2.176 & 2.410 \\
\hline & II & 40.1 & 1.1902 & 1.7644 & 1.5963 & 2.176 & 2.410 \\
\hline & III & 40.0 & 3.0230 & 2.1502 & 1.3231 & 2.176 & 2.410 \\
\hline \multirow{3}{*}{$\mathrm{C}-2$} & 1 & 41.3 & 1.6193 & 1.7291 & 1.3586 & 2.176 & 2.410 \\
\hline & II & 40.9 & 2.2986 & 1.0441 & 1.3486 & 2.176 & 2.410 \\
\hline & III & 41.7 & 1.7192 & 1.2797 & 1.3378 & 2.176 & 2.410 \\
\hline \multirow{3}{*}{$\mathrm{C}-3$} & 1 & 41.6 & 1.5184 & 1.7123 & 1.2513 & 2.176 & 2.410 \\
\hline & II & 42.6 & 2.5441 & 1.8081 & 1.5329 & 2.176 & 2.410 \\
\hline & III & 42.0 & 2.8087 & 2.1362 & 1.4241 & 2.176 & 2.410 \\
\hline \multirow{3}{*}{ C-4 } & 1 & 45.5 & 2.3034 & 1.3024 & 1.0853 & 2.176 & 2.410 \\
\hline & II & 39.5 & 3.8261 & 1.8295 & 1.6988 & 2.176 & 2.410 \\
\hline & III & 44.2 & 4.2505 & 1.5762 & 1.8222 & 2.176 & 2.410 \\
\hline \multirow{3}{*}{ C-5 } & 1 & 45 & 1.6245 & 1.8467 & 1.2311 & 2.176 & 2.410 \\
\hline & II & 41.8 & 1.6533 & 1.0887 & 1.3306 & 2.176 & 2.410 \\
\hline & III & 46.4 & 3.4705 & 2.1322 & 1.0373 & 2.176 & 2.410 \\
\hline \multirow{3}{*}{ C-6 } & 1 & 43.7 & 3.5707 & 1.7363 & 1.3442 & 2.176 & 2.410 \\
\hline & II & 47.6 & 3.4960 & 2.1739 & 1.2585 & 2.176 & 2.410 \\
\hline & III & 46.4 & 3.4705 & 2.1322 & 1.0373 & 2.176 & 2.410 \\
\hline \multirow{3}{*}{ C-7 } & 1 & 45.5 & 2.2174 & 1.3529 & 1.3529 & 2.176 & 2.410 \\
\hline & II & 49.1 & 2.5413 & 1.6133 & 1.3379 & 2.176 & 2.410 \\
\hline & III & 46.4 & 3.5839 & 2.0647 & 1.0045 & 2.176 & 2.410 \\
\hline \multirow{3}{*}{ C-8 } & 1 & 48 & 4.4721 & 1.7888 & 1.006 & 2.176 & 2.410 \\
\hline & II & 47.1 & 1.6124 & 1.3024 & 2.1087 & 2.176 & 2.410 \\
\hline & III & 50.4 & 4.2899 & 1.7249 & 1.5384 & 2.176 & 2.410 \\
\hline
\end{tabular}
sponding critical values at the chosen level of

Table 4. Uncertainty analysis of Rebound Index (R) results for castable cubes 
Table 5. UPV values and uncertainty analysis results

\begin{tabular}{|c|c|c|c|c|c|c|c|c|}
\hline \multirow{2}{*}{ Cube ID } & \multirow{2}{*}{ ID } & \multirow{2}{*}{$\begin{array}{c}\text { Travel } \\
\text { time }(\mu \mathrm{S})\end{array}$} & \multirow{2}{*}{$\begin{array}{l}\text { UPV } \\
\text { (m/sec) }\end{array}$} & \multirow{2}{*}{$\begin{array}{c}\text { Smallest } \\
\text { value }\end{array}$} & \multirow{2}{*}{$\begin{array}{l}\text { Largest } \\
\text { value }\end{array}$} & \multicolumn{2}{|c|}{ Significance level } & \multirow{2}{*}{$\begin{array}{c}\text { Average } \\
\text { UPV Results }\end{array}$} \\
\hline & & & & & & $5 \%$ & $1 \%$ & \\
\hline \multirow{3}{*}{$\mathrm{C}-0$} & I & 30.2 & 4966 & \multirow{3}{*}{0.808} & \multirow{3}{*}{0.192} & \multirow{3}{*}{0.941} & \multirow{3}{*}{0.988} & \multirow{3}{*}{5117} \\
\hline & II & 29.0 & 5168 & & & & & \\
\hline & III & 28.7 & 5216 & & & & & \\
\hline \multirow{3}{*}{$C-1$} & 1 & 27.3 & 5494 & \multirow{3}{*}{0.535} & \multirow{3}{*}{0.879} & \multirow{3}{*}{0.941} & \multirow{3}{*}{0.988} & \multirow{3}{*}{5563} \\
\hline & II & 27.2 & 5514 & & & & & \\
\hline & III & 26.4 & 5681 & & & & & \\
\hline \multirow{3}{*}{$\mathrm{C}-2$} & $\mathrm{I}$ & 26.8 & 5263 & \multirow{3}{*}{0.455} & \multirow{3}{*}{0.545} & \multirow{3}{*}{0.941} & \multirow{3}{*}{0.988} & \multirow{3}{*}{5425} \\
\hline & II & 27.7 & 5415 & & & & & \\
\hline & III & 28.5 & 5597 & & & & & \\
\hline \multirow{3}{*}{ C-3 } & I & 27.2 & 5263 & \multirow{3}{*}{0.606} & \multirow{3}{*}{0.853} & \multirow{3}{*}{0.941} & & \\
\hline & II & 28.3 & 5300 & & & & 0.988 & 5359 \\
\hline & III & 28.5 & 5514 & & & & & \\
\hline & 1 & 28.7 & 5119 & & & & & \\
\hline C-4 & II & 29.3 & 5226 & 0.285 & 0.715 & 0.941 & 0.988 & 5280 \\
\hline & III & 27.3 & 5494 & & & & & \\
\hline & 1 & 30.2 & 4854 & & & & & \\
\hline C-5 & II & 30.9 & 4966 & 0.262 & 0.737 & 0.941 & 0.988 & 5034 \\
\hline & III & 28.4 & 5281 & & & & & \\
\hline & $\mathrm{I}$ & 31.9 & 4702 & & & & & \\
\hline C-6 & II & 31.8 & 4716 & 0.077 & 0.923 & 0.941 & 0.988 & 4768 \\
\hline & III & 30.7 & 4885 & & & & & \\
\hline & 1 & 34.1 & 4373 & & & & & \\
\hline C-7 & II & 32.6 & 4398 & 0.109 & 0.890 & 0.941 & 0.988 & 4458 \\
\hline & III & 34.3 & 4601 & & & & & \\
\hline & 1 & 35.7 & 4201 & & & & & \\
\hline C-8 & II & 35.0 & 4285 & 0.694 & 0.306 & 0.941 & 0.988 & 4269 \\
\hline & III & 34.7 & 4322 & & & & & \\
\hline
\end{tabular}

significance of $5 \%$ and $1 \%$; the existence of an inlier is indicated [19]. The same procedure was adopted for uncertainty analysis of UPV results of all castable cubes and indicated in Table 5.

The direct transmission method is used to find out UPV. UPV test and its uncertainty results for $80 \% \mathrm{Al}_{2} \mathrm{O}_{3}$ castable cubes are presented in Table 5. Table 5 indicated that $\mathrm{C}-1$ exhibits a higher value of UPV than $\mathrm{C}-2$ to $\mathrm{C}-8$ as ceramic cracks not propagated at $100{ }^{\circ} \mathrm{C}$. C-8 showed $26.68 \%, 23.85 \%, 22.64 \%, 21.17 \%$, $16.44 \%, 11.04 \%, 4.33 \%$ less UPV value compared to C-1, C-2, C-3, C-4, C-5, C-6, C-7 respectively due to formation of micro-cracks inside the cube samples at an average increment of $100{ }^{\circ} \mathrm{C}$. Thus, the travel time of ultrasonic pulse waves is more in C-8 compared to other cube samples heated from $100{ }^{\circ} \mathrm{C}$ to $700{ }^{\circ} \mathrm{C}$. Thus, UPV gets reduced as the temperature rises for C-1, C-2, C-3, C-4, C-5, C-6, and C-7 subjected to $100{ }^{\circ} \mathrm{C}, 200{ }^{\circ} \mathrm{C}, 300{ }^{\circ} \mathrm{C}, 400{ }^{\circ} \mathrm{C}$, $500{ }^{\circ} \mathrm{C}, 600{ }^{\circ} \mathrm{C}$ and $700{ }^{\circ} \mathrm{C}$ heating temperature.

Compressive strength test results of $\mathrm{C}-0$ i.e. $\mathrm{x}_{1}$ $=34.70 \mathrm{~N} / \mathrm{mm}^{2}, \mathrm{x}_{2}=37.00 \mathrm{~N} / \mathrm{mm}^{2}$ and $\mathrm{x}_{\mathrm{n}}=37.50$ $\mathrm{N} / \mathrm{mm}^{2}$ arranged in the ascending order of magnitude. The smallest value $r_{10}=\frac{x_{2}-x_{1}}{x_{n}-x_{1}}$ and largest value $r_{10}=\frac{x_{n}-x_{n-1}}{x_{n}-x_{1}}$ calculated. The ratio of smallest and largest value does not cross beyond the corresponding critical values at the chosen level of significance of $5 \%$ and $1 \%$; the existence of an inlier is observed [19]. The same calculation was used for uncertainty analysis of compressive strength results of all castable cubes and indicated in Table 6 .

Table 6 depicted increase of average compressive strength by $13.33 \%, 19.13 \%, 23.30 \%$, $27.28 \%, 33.02 \%, 38.75 \%, 42.59 \%$ and $47.05 \%$ for C-1, C-2, C-3, C-4, C-5, C-6, C-7 and C-8 
Table 6. Cube compressive strength and uncertainty analysis results

\begin{tabular}{|c|c|c|c|c|c|c|c|}
\hline \multirow{2}{*}{ Cube ID } & \multirow{2}{*}{ ID } & \multirow{2}{*}{$\begin{array}{l}\text { Comp. Strength } \\
\left(\mathrm{N} / \mathrm{mm}^{2}\right)\end{array}$} & \multirow{2}{*}{$\begin{array}{l}\text { Smallest } \\
\text { value }\end{array}$} & \multirow{2}{*}{$\begin{array}{l}\text { Largest } \\
\text { value }\end{array}$} & \multicolumn{2}{|c|}{ Significance level } & \multirow{2}{*}{$\begin{array}{l}\text { Avg. Comp. } \\
\text { Strength }\left(\mathrm{N} / \mathrm{mm}^{2}\right)\end{array}$} \\
\hline & & & & & $5 \%$ & $1 \%$ & \\
\hline \multirow{3}{*}{ C-0 } & 1 & 34.70 & \multirow{3}{*}{0.821} & \multirow{3}{*}{0.179} & \multirow{3}{*}{0.941} & \multirow{3}{*}{0.988} & \multirow{3}{*}{36.4} \\
\hline & II & 37.00 & & & & & \\
\hline & III & 37.50 & & & & & \\
\hline \multirow{3}{*}{ C-1 } & 1 & 40.85 & \multirow{3}{*}{0.667} & \multirow{3}{*}{0.337} & \multirow{3}{*}{0.941} & \multirow{3}{*}{0.988} & \multirow{3}{*}{41.60} \\
\hline & II & 41.75 & & & & & \\
\hline & III & 42.20 & & & & & \\
\hline \multirow{3}{*}{ C-2 } & 1 & 43.30 & \multirow{3}{*}{0.297} & \multirow{3}{*}{0.703} & \multirow{3}{*}{0.941} & \multirow{3}{*}{0.988} & \multirow{3}{*}{44.10} \\
\hline & II & 43.85 & & & & & \\
\hline & III & 45.15 & & & & & \\
\hline \multirow{3}{*}{ C-3 } & 1 & 44.85 & \multirow{3}{*}{0.865} & \multirow{3}{*}{0.135} & \multirow{3}{*}{0.941} & \multirow{3}{*}{0.988} & \multirow{3}{*}{46.00} \\
\hline & II & 46.45 & & & & & \\
\hline & III & 46.70 & & & & & \\
\hline & 1 & 46.80 & & & & & \\
\hline C-4 & II & 48.10 & 0.650 & 0.350 & 0.941 & 0.988 & 47.90 \\
\hline & III & 48.80 & & & & & \\
\hline & 1 & 49.50 & & & & & \\
\hline C-5 & II & 51.25 & 0.795 & 0.205 & 0.941 & 0.988 & 50.80 \\
\hline & III & 51.70 & & & & & \\
\hline & 1 & 52.10 & & & & & \\
\hline C-6 & II & 54.40 & 0.742 & 0.258 & 0.941 & 0.988 & 53.90 \\
\hline & III & 55.20 & & & & & \\
\hline & 1 & 54.30 & & & & & \\
\hline C-7 & II & 55.90 & 0.421 & 0.579 & 0.941 & 0.988 & 56.10 \\
\hline & III & 58.10 & & & & & \\
\hline & 1 & 58.00 & & & & & \\
\hline C-8 & II & 58.70 & 0.412 & 0.588 & 0.941 & 0.988 & 58.80 \\
\hline & III & 59.70 & & & & & \\
\hline
\end{tabular}

compared to $\mathrm{C}-0$ at $100{ }^{\circ} \mathrm{C}, 200^{\circ} \mathrm{C}, 300^{\circ} \mathrm{C}, 400{ }^{\circ} \mathrm{C}$, $500{ }^{\circ} \mathrm{C}, 600{ }^{\circ} \mathrm{C}, 700{ }^{\circ} \mathrm{C}$ and $800{ }^{\circ} \mathrm{C}$ heating temperature, respectively. The phenomenon of ceramic bonding of $\mathrm{Al}_{2} \mathrm{O}_{3}$ at an increment of $100{ }^{\circ} \mathrm{C}$ provides additional resistance to the applied compressive loading similar to [17].

\section{Relationship between direct and indirect laboratory results}

A comparative graph between compressive strength, ultrasonic pulse velocity, and rebound number prepared for developing a co-relationship between direct versus indirect testing results. It is presented in the form of Figures 9 to 11 .

Figure 9 showed a proportionality relationship between rebound test compressive strength and destructive compressive strength for all the specimens subjected to $100{ }^{\circ} \mathrm{C}, 200{ }^{\circ} \mathrm{C}, 300{ }^{\circ} \mathrm{C}, 400{ }^{\circ} \mathrm{C}, 500$
${ }^{\circ} \mathrm{C}, 600{ }^{\circ} \mathrm{C}, 700{ }^{\circ} \mathrm{C}$ and $800{ }^{\circ} \mathrm{C}$ heating temperature. Cube specimens $\mathrm{C}-1$ and $\mathrm{C}-2$ showed a relatively close connection between destructive compressive strength and rebound test compressive strength.

Figure 10 showed a non-proportionality relationship between rebound test compressive

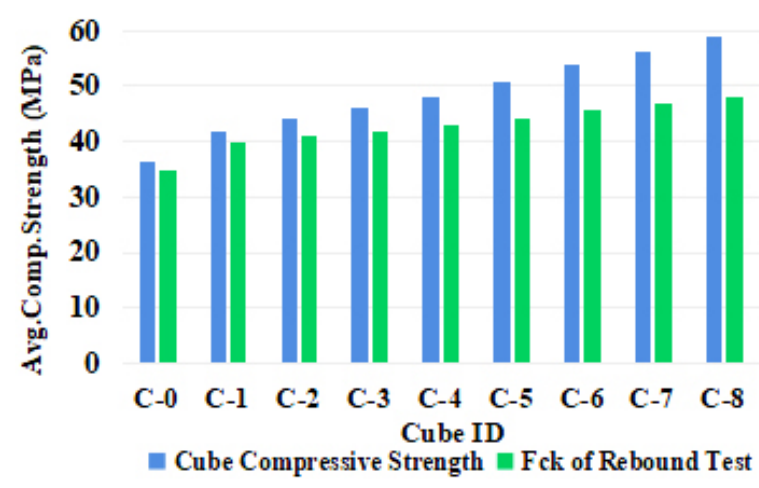

Fig. 9. Direct and rebound test comp. strength for castable cubes 


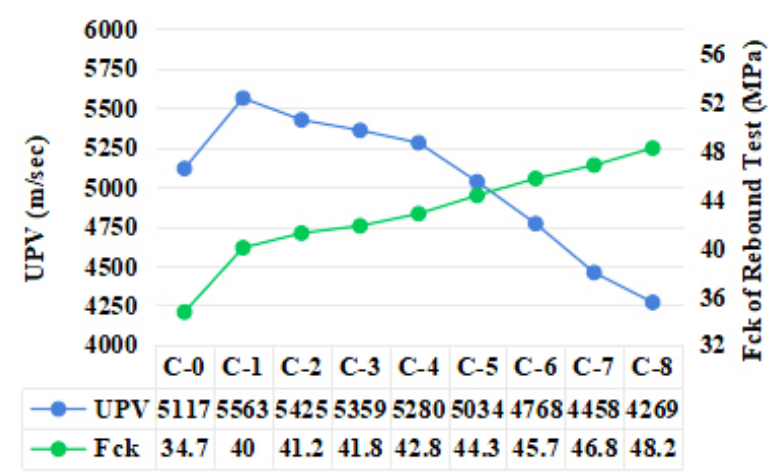

Fig. 10. Rebound test comp.strength and UPV for castable cubes

strength and UPV for all the specimens of C- $0, \mathrm{C}-1$, C-2, C-3, C-4, C-5, C-6, C-7 and C-8 subjected to $100{ }^{\circ} \mathrm{C}, 200{ }^{\circ} \mathrm{C}, 300{ }^{\circ} \mathrm{C}, 400{ }^{\circ} \mathrm{C}, 500{ }^{\circ} \mathrm{C}, 600$ ${ }^{\circ} \mathrm{C}, 700{ }^{\circ} \mathrm{C}$ and $800{ }^{\circ} \mathrm{C}$ heating temperature. The Rebound test compressive strength is increasing, whereas UPV decreases for all three specimens due to the formation of micro-cracks within cubes.

The UPV test values were plotted with cube compressive strength of $80 \% \mathrm{Al}_{2} \mathrm{O}_{3}$ castable, as shown in Figure 11. It showed UPV values go down as the temperature rises, whereas cubes' compressive strength significantly improved concerning temperature. Change in compressive strength increased due to the evaporation of water vapor that is present in the matrix. In addition to this, the ceramic bonding effect, which increases the strength of cubes after heating. The dense refectory material tends to get more substantial up to $800{ }^{\circ} \mathrm{C}$ because particles get fused and fill the void created by escaping moisture. Due to this phenomenon, the compressive strength of the refractory goes up. In contrast, due to micro-cracks inside the cube, the time travel increases, and UPV gets reduced as the temperature rises.

Results of the Non-destructive method were found effectively in structural strength assessment

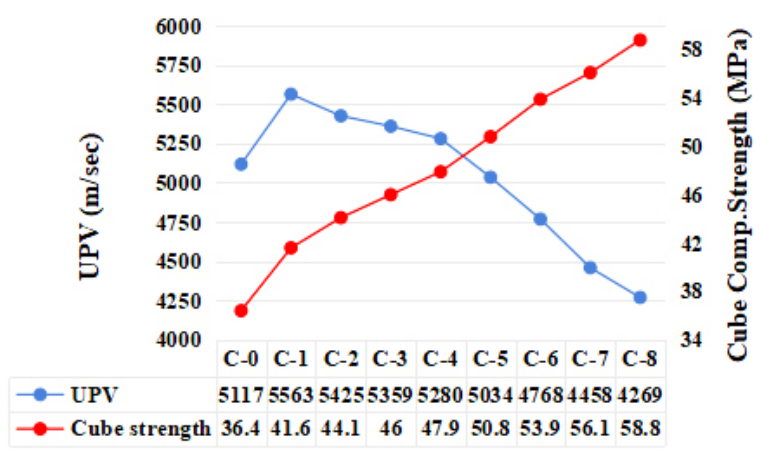

Fig. 11. Cube compressive strength and UPV values for castable cubes by examining and monitoring the extent of the damage, accord to a finding of Sadri et al. [1]. NDT methods are primarily dependent on the standard and isotropic nature of the refractory materials of refractory lining, as observed by Sadri et al. [2]. Periodic NDT assessment helps to extend both the refractory's age and the valuable period of its structural components in close affirmation with Gebski et al. [3]. Rebound Hammer cannot provide an accurate estimate of concrete strength. It is most likely due to the test's small area, allowing minor local inhomogeneities to influence the test. As a result, similar to Brencich et al. [4], the rebound hammer appears ineffective in estimating concrete compressive strength, serving only as a rough tool for assessing material homogeneity within a specific concrete type. Thermal expansion loading applied to refractory structures. The compressive and flexural strengths of refractory materials vary linearly with temperature. High temperatures have a more significant impact on the properties of refractory materials. Refractory materials do not behave elastic as temperatures change. It appears to be an excellent correlation with Awchat's observation [5]. NDT methods have been used to monitor concrete structures for more than three decades; it is now recognized that NDT plays a vital role in monitoring existing RC structures. According to Verma et al. [6], NDT methods are more practical for assessing and evaluating the condition of $\mathrm{RC}$ structures. Structures subjected to extreme thermal loading revealed refractory element behavior to be more complex than Essen et al. [13].

The two most commonly used nondestructive testing (NDT) methods are radiography and ultrasonics. These two techniques apply to any structural engineering material, including refractories. It observed that ultrasonics do not yield high resolution in crack detection or thickness measurements in porous media like refractory concretes. Such areas tend to be highly attenuated to ultrasonic waves. Binder material and between the concrete and internal voids oppose the free movement of pulses. On the other hand, the penetrating radiation methodology of NDT is not subject to severe scattering in these materials and is highly useful, and results are in agreement with Ellingson [20]. In the pulse-echo method, a transducer made of piezoelectric material (also called a probe) transmits a pulse of mechanical energy into the component. The energy passes into the material in the pulse-echo method of NDT, reflects from the back surface, and is detected by the same transducer, 
yielding a signal on an oscilloscope with a timebase. The oscilloscope would typically show the original pulse of the ultrasonic transducer (front surface echo), the back reflection, and any extra blip indicating a reflection from a defect in the material. Results are in close comparison with the findings of Raj et al. [21].

\section{Relationship of UPV \& MoR laboratory test results}

The relationship between UPV and MoR for B-1, B-2, B-3 \& B-4 is presented in Figures 12 to 15 , respectively. Figure 12 indicated that UPV is in decreasing order for $0,2,4,6,8$, and 10 heating cycles. MoR decreased due to the formation of micro-cracks in B-1 clay-based brick samples. There was no observation of surface cracks in all B-1 brick samples after $0,2,4,6,8$, and 10 heating cycles. More micro-cracks inside B-1 need to travel ultrasonic pulses to take more time, leading to a lesser value of UPV after the 4th heating cycle.

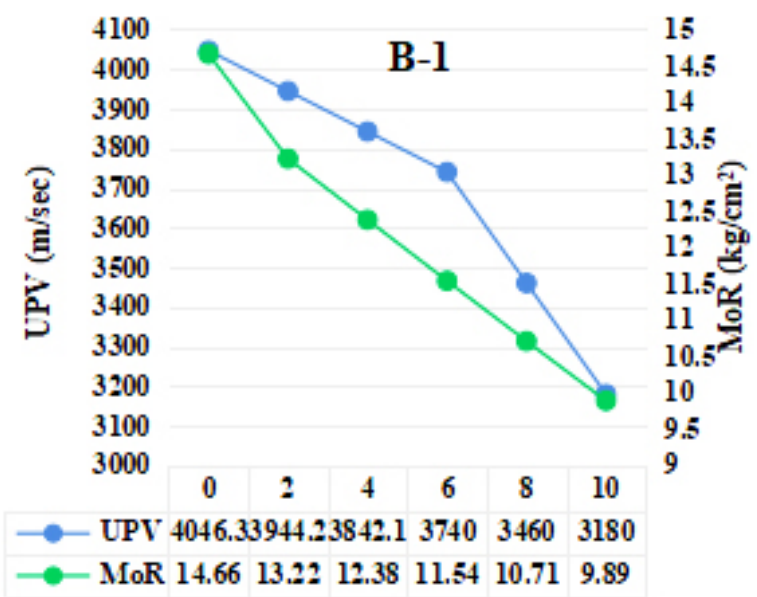

Fig. 12. UPV and MoR results for B-1

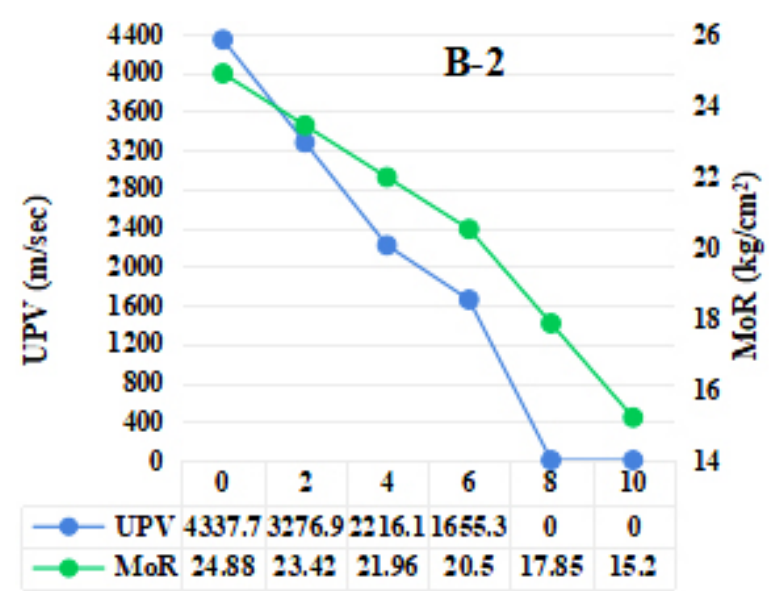

Fig. 13. UPV and MoR results for B-2
Figure 13 indicated that B-2 showed a lesser MoR value due to glassy phase formation in the system due to the blending of clay and lowgrade high alumina material. This induced more micro-cracks inside the system. UPV test result also showed no reading after the 6 th cycle. More micro-cracks inside B-2 need more time travel ultrasonic pulses, tending to a lesser value of UPV after 2 nd heating cycle. After the 6th cycle, B-2 showed cracks on a surface, which means macro cracks inside the samples. After the 6th cycle, more significant cracks were noticed on the complete samples, as presented in Figure 18.

Figure 14 showed that the UPV is relatively increased than B-1 and B-2 brick samples for all $0,2,4,6,8$, and 10 heating cycles. MoR in B-3, i.e., bauxite-based brick samples increased at 0,2 , $4,6,8$, and 10 heating cycles due to the ceramic bonding effect of brick samples. Surface cracks were not observed in any of the B-3 brick samples after all heating cycles. Because of the nonpresence of microcracks in B-3, ultrasonic pulses

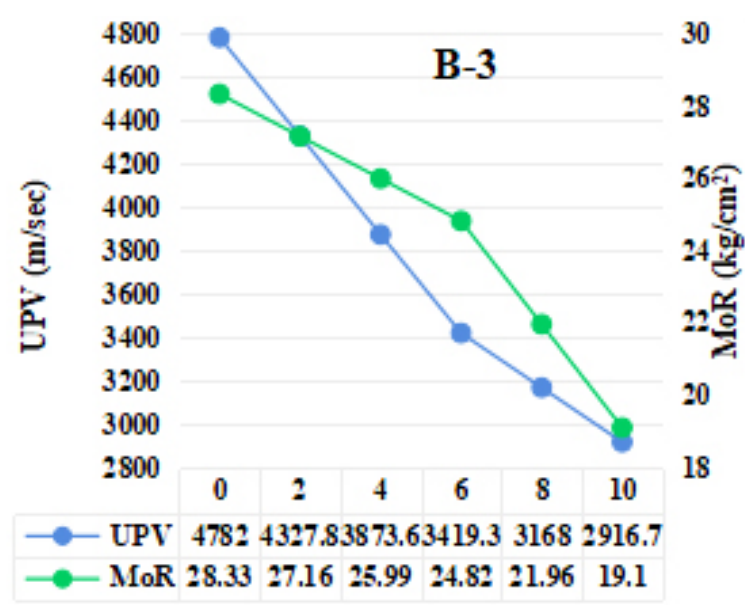

Fig. 14. UPV and MoR results for B-3

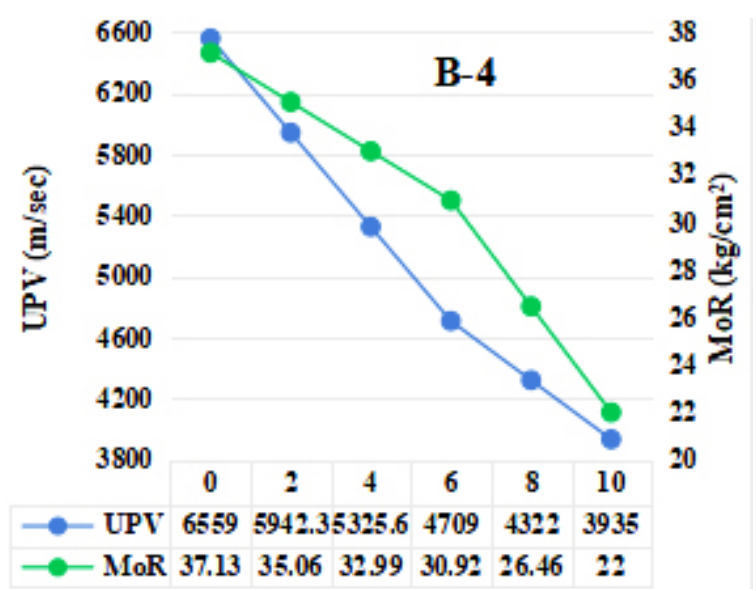

Fig. 15. UPV and MoR results for B-4 
must travel for a shorter distance, resulting in a higher UPV value at $0,2,4$, and 6 heating cycles.

Figure 15 depicted that B-4 showed a higher MoR value than B-1, B-2, and B-3 brick samples due to glassy phase formation in the sample due to the blending of phosphate and high-grade alumina material. UPV is an increasing trend for 0,2 , $4,6,8$, and 10 heating cycles. MoR was observed more due to the development of no cracks in B-4 phosphate bonded high alumina bricks. There was no observation of surface cracks in all B-4 brick samples after $0,2,4,6,8$, and 10 heating cycles.

Figure 16 presented the percentage of MoR reduction, and Figure 17 indicated a percentage reduction of UPV for all bricks. Figure 16 showed that the decrease in MoR for B-1 was minor compared to B-4 and observed the same in UPV results as presented in Figure 17. UPV indicates the micro-crack propagation was very high in B-2 as compared to B-4. However, the same percentage of reduction was noticed in B-3 compared with B-1, which is pure bauxite bricks

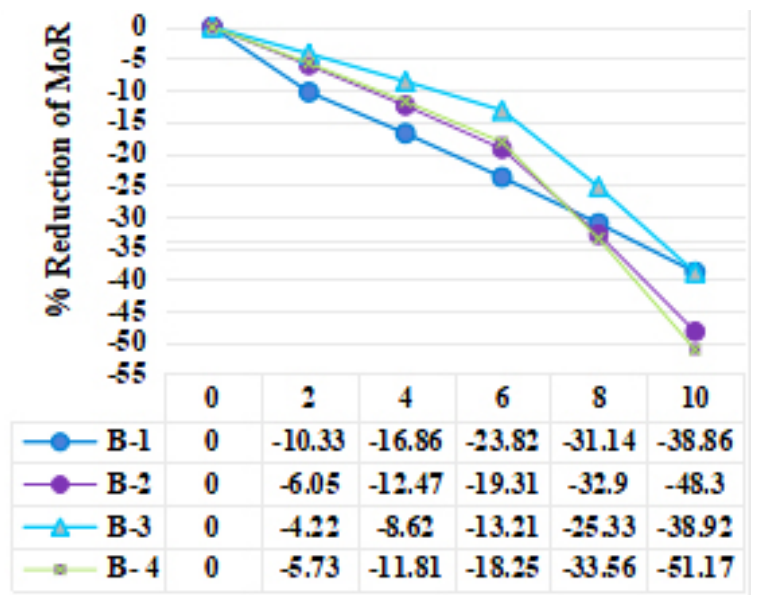

Fig. 16. \% reductions of MoR for bricks

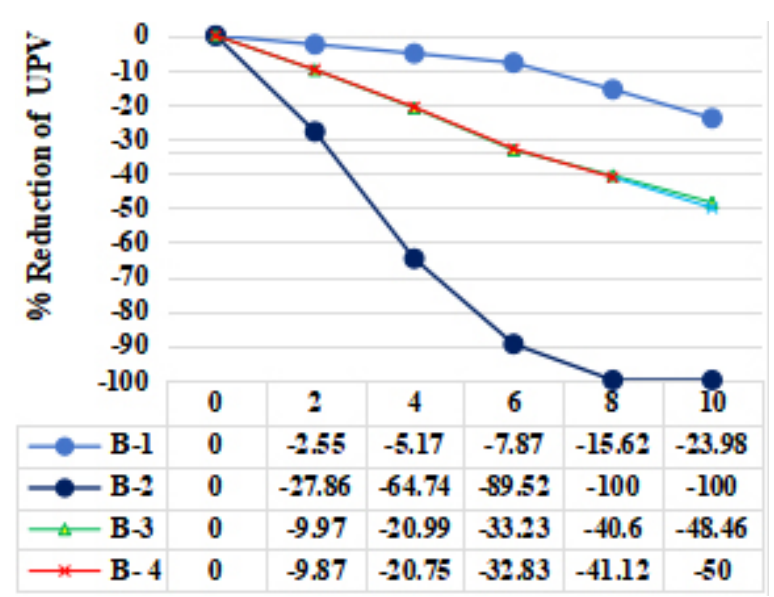

Fig. 17. \% reductions of UPV for bricks

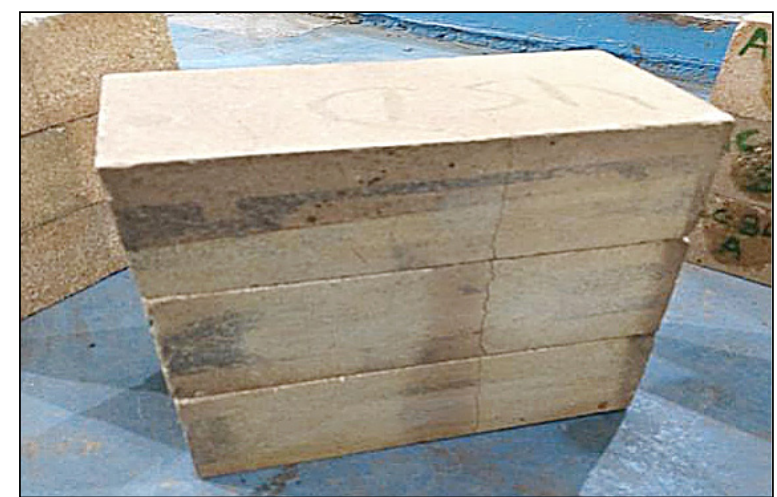

Fig. 18. Sample B-2 cracked after 6 cycles

without any additional bonding system. All these bricks are made of different compositions and raw materials to check whether this brick can resist thermal cracks. Only B-2 bricks get complete crack throughout the width after 6 cycles which are seen in Figure 18, whereas other bricks correlate perfectly with MoR value, and the trend between MoR and UPV results is similar.

According to the current study, refractories are more heat-safe than metals, which is consistent with the findings of Sadik et al. [16].The high accuracy rate of UPV test results is suitable for further investigations to establish a reliable MoR results similar to Bolborea et al. [18].Ultrasound interacts with macro-structural grains and pores as a function of wavelength. Therefore, the ultrasound equipment did not reveal the fine microstructural variances detected with radar. The indicated cavity position in the cavity reduced block depended on the cavity back wall echo. It did not correlate to the actual cavity location as observed by radiography, similar to findings of Heidrich [22]. The sound velocities along with three directions of refractory ceramic brick specimens of size $300 \mathrm{~mm}$ (width) $\times 270 \mathrm{~mm}$ (length) $\times 20 \mathrm{~mm}$ (height were measured using the ultrasonic through-transmission technique. The measurement was conducted by attaching a transmitting transducer and receiving transducer on the opposite planes of each face. The results obtained are similar to Lee et al. [23].

\section{CONCLUSIONS}

Following were salient conclusions drawn from this study:

- Rebound number provides a rough idea about the homogeneity of $80 \% \mathrm{Al}_{2} \mathrm{O}_{3}$ castable cube specimens material as it gave only the surface hardness indication. 
- Uncertainty analysis of Rebound index (R) obtained from schmidt digital rebound hammer validated that results obtained for all castable cubes are within significance level of acceptance.

- UPV Results observed helpful in identifying the development of microcrack formation by observing UPV value.Uncertainty analysis also justified that all UPV values are inlier and validated equipment.

- UPV Test conducted encouraged more research for other refractory materials beyond $800{ }^{\circ} \mathrm{C}$ heating temperature.

- Compressive strength obtained from rebound test is $4.78 \%, 3.92 \%, 6.79 \%, 9.56 \%$, $11.24 \%, 13.66 \%, 16.47 \%, 18.07 \%$ and $19.81 \%$ less compared to cube compressive strength results of C-0, C-1, C-2, C-3, C-4, C-5, C-6, C-7 and C-8 subjected to $100{ }^{\circ} \mathrm{C}$, $200{ }^{\circ} \mathrm{C}, 300{ }^{\circ} \mathrm{C}, 400{ }^{\circ} \mathrm{C}, 500{ }^{\circ} \mathrm{C}, 600{ }^{\circ} \mathrm{C}$, $700{ }^{\circ} \mathrm{C}$ and $800{ }^{\circ} \mathrm{C}$ heating temperature.It indicated that rebound test and cube compressive strength is within a difference of $20 \%$ up to $800^{\circ} \mathrm{C}$ heating temperature.Uncertainty analysis also justified that all cube compressive strength results are inlier and validated equipment.

- UPV test results showed the material degradation at 2, 4, 6, 8 and 10 heating cycles for all brick samples.

- UPV test observed to be a suitable method that could validate the qualitative strength of any refractory materials.

- Compressive strength increased due to the evaporation of water vapor that is present in the matrix of high alumina bricks. In addition to this, the ceramic bonding effect, which increases the strength of cubes after heating. The dense refectory material gets more substantial up to $800{ }^{\circ} \mathrm{C}$ or beyond because particles get fused and fill the void created by escaping moisture. Due to this phenomenon, the compressive strength of the refractory increase, and such refractory material can be used for higher temperature cycles.

- Phosphate bonded high alumina bricks, i.e., B-4 showed good UPV and MoR test results compared to other brick samples at $800{ }^{\circ} \mathrm{C}$ heating temperature.

- It is strongly recommended to adopt phosphate bonded high alumina material for refractory furnace lining unit.

\section{REFERENCES}

1. Sadri A., Ying W.L., Erskine J., Macrosty R. Smelting furnace non-destructive testing and monitoring. In: 19th World Conference on Non - Destructive Testing, Munich, Germany 2016, 1-12.

2. Sadri A., Ying W.L., Chatway D. Non-destructive testing and monitoring of refractory lining in operating furnaces. In: Centro Parque Convention and Conference Center, Santiago, Chile 2017, 238-241.

3. Gebski P., Shameli E., Sadri A. Non-destructive testing techniques for determination of refractory deterioration in smelting furnaces. Pyrometallurgy in Southern Africa, 2009.

4. Brencich A., Cassini G., Pera D., Riotto G. Calibration and reliability of the rebound (Schmidt) hammer Test. Civil Engineering and Architecture. 2013;1(3):66-78. DOI: 10.13189/ cea.2013.010303.

5. Awchat G. Analysis of structural element in refractory industries. International Journal of Advanced Research in Engineering and Technology. 2020; 11(10): 384-393. DOI: 10.34218/IJARET.11.10.2020.041

6. Verma S.K., Bhadauria S.S., Akhtar S. Review of non-destructive testing methods for condition assessment of Concrete Structures. Journal of Construction Engineering. 2013;1-11. DOI: 10.1155/2013/834572.

7. Almir P.F., Protasio F.C. Application of NDT to concrete strength estimation. NDT.Net. 2000;5(2):1-6.

8. Bhadauria S.S., Gupta D.M.C. In situ performance testing of deteriorating water tanks for durability assessment. Journal of Performance of Constructed Facilities. 2007; 21(3): 234-239.

9. Maierhofer C., Reinhardt H.W., Dobmann G. Nondestructive evaluation of reinforced concrete structures. Woodhead Publishing; 2010.

10. IS-13311.Non-destructive Testing of concretemethods of a test, Part 2: rebound hammer. Bureau of Indian Standards; 1992.

11. IS-518. Hardened concrete - method of test, part 5: non-destructive testing of concrete -. section 1: ultrasonic pulse velocity testing. Bureau of Indian Standards; 2018.

12. Schacht C. Properties of refractories, in Refractories Handbook. CRC Press; 2004.

13. Essen V.V. Design (chapter 3). In: Refractory engineering materials-design-construction, second Edition.German Association of Refractory and Chimney Engineering. 2005; 67-197.

14. Walker H. Classes of Refractories (section 2). In: Handbook of Refractory Practice, Harbison Walker Refractories Company, Moon Township, PA, 2005, 9-31. 
15. Weidner A., Klemm Y.R., Zienert T., Aneziris C.G., Biermann,H. Mechanical high - temperature properties and damage behavior of coarsegrained alumina refractory metal Composites. Materials. 2019;12(3927):2-12. DOI: 10.3390/ ma12233927.

16. Sadik C., Amrani E. E., Albizane, A. Recent advances in silica-alumina refractory:a review, Journal of Asian Ceramic Societies. 2014; (2): 83-96.

17. Frulli D., Heever D. Andalusite-based raw materials for refractory castable: properties and application.IMERYS Refractory Minerals. 2018; 1-6.

18. Bolborea B., Dan S., Matel C., Gruin A., Baeră C., Perianu, I.A. Estimating the concrete compressive strength using the concrete ultrasonic pulse velocity and moduli of elasticity. Advanced Materials Research. 2021; (1164): 77-86.
19. IS:8900.Criteria for the rejection of outlaying observations [MSD 3:statistical methods for quality and reliability. Bureau of Indian Standards; 1978.

20. Ellingson W.A. Advances in non-destructive evaluation methods for inspection of refractory concretes. In:Symposium on premature failure in monolithic refractory construction, Las Vegas, Nevada 1980, 1-30.

21. Raj B., Jayakumar T., Rao B.P.C. Non-destructive testing and evaluation for structural integrity.Sadhana.1995: 20(1): 5-38.

22. Heidrich R.Non-destructive testing of fused cast refractory blocks for glass melting tanks using Radar Technology. RHI Bulletin; 2014.

23. Lee S., Shin N., Roh Y. Estimation of the thickness of refractory ceramics using the impact-echo method. The Journal of the Acoustical Society of Korea. 2017; 36(4): 247-253. DOI: 10.7776/ASK.2017.36.4.247. 